\title{
Photosynthesis in relation to D1, PsaA and Rubisco in marine and brackish water ecotypes of Fucus vesiculosus and Fucus radicans (Phaeophyceae)
}

\author{
A. Maria Gylle · Charlotta A. Nygård • \\ Carina I. Svan · Tessa Pocock • \\ Nils G. A. Ekelund
}

Received: 26 January 2012/Revised: 4 June 2012/ Accepted: 7 June 2012/Published online: 5 July 2012

(C) The Author(s) 2012. This article is published with open access at Springerlink.com

\begin{abstract}
The aim of this study was to investigate photosynthetic differences between the marine, Norwegian Sea ecotype and the brackish, Bothnian Sea ecotype of $F$. vesiculosus and $F$. radicans and to see whether photosynthetic differences could be connected with the relative amounts of D1 protein (PSII), PsaA (PSI) protein and/or Rubisco. For this purpose, we tested if a higher photosynthetic maximum $\left(P_{\max }\right)$ in the Atlantic Ocean ecotype of $F$. vesiculosus relative to the Baltic Sea ecotype, and an increase of the $P_{\max }$ in Baltic Sea ecotype of $F$. vesiculosus at higher salinity, could be due to an increase in the relative amounts of Rubisco. The proteins have been evaluated on a relative basis. Immunoblot signals showed that the amount of Rubisco was higher in both ecotypes of $F$. vesiculosus than in $F$. radicans, but no differences could be detected between the two ecotypes of
\end{abstract}

Handling editor: Luigi Naselli-Flores

A. M. Gylle · C. I. Svan · N. G. A. Ekelund ( $\square)$

Department of Natural Sciences, Engineering and Mathematics, Mid Sweden University, 85170 Sundsvall, Sweden

e-mail: nils.ekelund@miun.se

\section{A. Nygård}

Department of Environment, County Administration Västernorrland, 87186 Härnösand, Sweden

T. Pocock

Heliospectra AB, Armbågavägen 3, 50630 Borås, Sweden
F. vesiculosus. The results suggest an uneven photosystem protein stoichiometry in Fucus, with more of the PSI protein PsaA relative to the PSII protein D1. The difference in $P_{\max }$ between the two ecotypes of $F$. vesiculosus might be related to the difficulties for the algae to adapt to the environment in Bothnian Sea.

Keywords D1 - Fucus radicans $\cdot$ Fucus vesiculosus . Photosynthetic maximum capacity $\left(P_{\max }\right) \cdot$ PsaA . Rubisco

\section{Introduction}

The brown alga Fucus vesiculosus L. is mainly a marine, North Atlantic, intertidal species (Powell, 1963), but the alga also grows in the sublittoral of the brackish Baltic Sea, along a salinity gradient down to the range of 2-4 psu (Wærn, 1952). Before the recent discovery of Fucus radicans L. Bergström et L. Kautsky (Bergström et al., 2005), F. vesiculosus was thought to be the only large belt-forming algal species in the Bothnian Sea, a northerly part of the Baltic Sea (Wallentinus, 1979). F. radicans is most certainly endemic to the Baltic Sea, grows side-by-side with $F$. vesiculosus and was earlier thought to be the same species.

The environmental factors differ greatly between the Norwegian Sea (part of the Atlantic Ocean) and the Bothnian Sea (part of the Baltic Sea). In contrast to the 
marine tidal Norwegian Sea (34 practical salinity units, psu), the Bothnian Sea has low salinity (4-5 psu), no tides and periodically an ice-cover. Environmental factors fluctuate rapidly for algae in the tidal zone of the Norwegian Sea. The differences in the local environments between the Norwegian Sea and the Bothnian Sea have given rise to differences in morphology as well as different physiological acclimation and/or adaptation capacities and mechanisms in the marine Norwegian Sea and the brackish Bothnian Sea ecotypes of $F$. vesiculosus. The brackish ecotype of $F$. vesiculosus is smaller with a thinner thallus (Kalvas \& Kautsky, 1993), has greater respiration rates, lower maximum photosynthetic capacities $\left(P_{\max }\right)$, lower mannitol concentration, lower tolerance of emersion stress and contains fewer water soluble organic compounds than the marine ecotype of F. vesiculosus (Bäck et al., 1992; Ruuskanen \& Bäck, 1999; Pearson et al., 2000; Nygård \& Ekelund, 2006; Gylle et al., 2009a, b).

An important protein, involved in linear electron transport in oxygenic photosynthesis, is the chlorophyll (Chl) $a$-binding core protein D1 (PsbA, $37 \mathrm{kDa}$ ) in the photosystem II (PSII) reaction centre. The D1 protein is rapidly cycled during illumination and disruption of D1 protein cycling or losses of D1 protein pools are central to the photoinhibition of photosynthesis (Nixon et al., 2005; reviewed by Nixon et al., 2010). One of the important proteins in the photosystem I (PSI) reaction centre is the Chl $a$ binding core protein, PsaA (82-83 kDa; Hall \& Rao 1999; reviewed by Santabarbara et al. 2010). PSI is involved in linear electron transport as well as cyclic electron transfer around PSI. The energy generated in the electron transport chain is stored in ATP and the reducing power is stored in NADPH. ATP and NADPH are used in the photosynthetic rate-limiting step of fixation of $\mathrm{CO}_{2}$ by ribulose-1,5-bisphosphate carboxylase/oxygenase (Rubisco). The most common structure of Rubisco consists of eight large (L) subunits (50-55 kDa) and eight small (S) subunits (15 kDa), $\mathrm{L}_{8} \mathrm{~S}_{8}$ ( $\sim 550 \mathrm{kDa}$; Raven, 1997).

$P_{\max }$ is lower in the Baltic Sea ecotype compared to the Atlantic Ocean ecotype of $F$. vesiculosus and if the Baltic Sea ecotype is kept for 1 week or longer in higher salinity (10-35 psu) the $P_{\max }$ increases considerably (Bäck et al., 1992; Nygård \& Ekelund, 2006; Nygård \& Dring, 2008). The reason for the higher $P_{\max }$ in the Atlantic Ocean ecotype of $F$. vesiculosus relative to the Baltic Sea ecotype, and for the increase of the $P_{\max }$ in Baltic Sea ecotype of $F$. vesiculosus at higher salinity, have been suggested to be either an increase in the relative amounts of Rubisco, or an upregulation of its activity (Nygård \& Dring, 2008).

The aim of this study was therefore to investigate photosynthetic differences between the marine, Norwegian Sea ecotype and the brackish, Bothnian Sea ecotype of $F$. vesiculosus and to see whether the photosynthetic differences could be connected with the relative amounts of D1 protein (PSII), PsaA (PSI) protein and/or Rubisco.

Fucus radicans was also included in this study in order to investigate if the native Bothnian Sea species shows other adaptations to the environment than in the original marine $F$. vesiculosus ecotype in the Bothnian Sea. The proteins have not been evaluated in absolute terms and therefore the amounts of D1 (PSII), PsaA (PSI) and Rubisco are compared among the algae on a relative basis. Further to this, the aim was to see whether the photosynthetic differences could be connected with the relative amounts of D1 protein, (PSII), PsaA (PSI) protein and/or Rubisco when the brackish Bothnian Sea ecotype of $F$. vesiculosus was affected by varying salinities $(5,10,20$ and 35 psu) in the short-term.

\section{Materials and methods}

Algal material

Fucus vesiculosus samples were collected from the intertidal area of the Norwegian Sea at Trondhjem Biological Station (Norway; 63 $43^{\prime} \mathrm{N} ; 10^{\circ} 39^{\prime} \mathrm{E}$; $34 \mathrm{psu}$ ) and from 2 to $4 \mathrm{~m}$ depth from the Bothnian Sea on the East side of Astön (Sweden; $62^{\circ} 24^{\prime} \mathrm{N}$; $17^{\circ} 45^{\prime} \mathrm{E}$; 4-5 psu). F. radicans was collected from the Bothnian Sea at the same time and place as $F$. vesiculosus. The samples were collected in May 2006 and the water temperature was $6-8^{\circ} \mathrm{C}$. The algae were transported in their natural water and darkness to the laboratory. Five individual samples of $F$. vesiculosus from the Bothnian Sea were prepared for an experiment as described below. For the aim of measuring the relative amounts of photosynthetic proteins from the collected algae groups, epiphytes were removed and tissue from the vegetative parts of the algal tips from ten individuals of each ecotype of $F$. vesiculosus and 
from ten individuals of $F$. radicans were immediately ground separately with a mortar and pestle in liquid $\mathrm{N}_{2}$ and frozen at $-80^{\circ} \mathrm{C}$ until use. To establish the electron transport rates (ETR) in the three algal groups, fresh thallus from five individuals of each ecotype of $F$. vesiculosus and from five individuals of $F$. radicans were collected at the same places as above in February to March, 2010. The water temperature was $0-4^{\circ} \mathrm{C}$. ETR was measured within $24 \mathrm{~h}$ after arrival to the laboratory and the samples were kept in darkness at $6^{\circ} \mathrm{C}$ until measurements.

Acclimation to changed salinity

For each experiment, an individual of $F$. vesiculosus from the Bothnian Sea was cleaned from epiphytes (approximately 10-15 cm long parts of thallus were used) and separated into five samples with two to four branches (depending on size) per sample. One of the samples was placed in Bothnian seawater (BSW, normal salinity 4-5 psu) and four samples in 5 psu artificial seawater (ASW), each in an individual $7 \mathrm{~L}$ aquarium. This was repeated with five individuals, so that in the salinity experiment each assay was done on five samples from different individuals. ASW was a mixture of deionised water, sea salt (Instant Ocean, United Pet Group, Cincinnati, OH, USA), inorganic compounds $\left(0.344 \mathrm{mg} \mathrm{L}^{-1} \quad \mathrm{NH}_{4} \mathrm{Cl}, \quad 2.05 \mathrm{mg} \mathrm{L}^{-1}\right.$ $\mathrm{NaNO}_{3}$ and $0.016 \mathrm{mg} \mathrm{L}^{-1} \mathrm{NaH}_{2} \mathrm{PO}_{4}$ ) and bicarbonate (1 mM $\mathrm{NaHCO}_{3}$, Sigma-Aldrich, St. Louis, MO, USA). The concentrations of inorganic compounds were chosen to be similar to those in BSW, according to an analysis done by LMI AB, Helsingborg, Sweden, and the concentration of bicarbonate was the same as in BSW (Raven \& Samuelsson, 1988). Before changing salinity, algae were allowed to acclimate for 3 days to the irradiance, temperature and basic growth medium. Thereafter, samples incubated in ASW were placed in salinities of $5,10,20$ or $35 \mathrm{psu}$; the sample in BSW was kept as a control. The growth medium was changed every 2.5 days and after 1 week of treatment, tissue from the vegetative parts of the algal tips (approximately three $\mathrm{cm}$ of each tip) was ground in liquid $\mathrm{N}_{2}$ and frozen at $-80^{\circ} \mathrm{C}$ until use. During the whole experiment, the algae were kept in 12-h darklight rhythm at the irradiance of $90 \mu \mathrm{mol}$ photons $\mathrm{m}^{-2} \mathrm{~s}^{-1}$ (Philips Master TL-D $36 \mathrm{~W} / 840$, Amsterdam, the Netherlands; measured with
LI-COR LI-189 quantum sensor, Lincoln, NE, USA) at $6-8^{\circ} \mathrm{C}$.

\section{Electron transport}

For the measurements of the ETR from the five individuals of each ecotype of $F$. vesiculosus and $F$. radicans, tissues from the vegetative parts of the algal tips were used. ETR was estimated from Chl $a$ fluorescence measurements by rapid light curves using a pulse amplitude modulated fluorometer (Diving PAM, Walz, Effeltrich, Germany). After an initial dark-adaptation of $20 \mathrm{~min}$, nine steps with increasing irradiance between 0 and $700 \mu \mathrm{mol}$ photons $\mathrm{m}^{-2} \mathrm{~s}^{-1}$ (30 s at each step) were used to induce photosynthesis, interrupted by dark periods of $2 \mathrm{~min}$. The temperature was kept approximately at $8^{\circ} \mathrm{C}$ during the measurements. ETR was measured at three different points at each thallus tip $(n=5)$ and the mean of the three measurements was used as each individual ETR. The ETR was calculated as:

$\mathrm{ETR}=\mathrm{PAR} \times \mathrm{AF} \times \Delta F / F_{\mathrm{m}}^{\prime} \times 0.5$

AF (the absorption factor) is the fraction of incident PAR absorbed by the thalli (plant tips, $n=5$ ) and was estimated according to the method of Beer et al. (2000) and Nygård \& Dring (2008). The AF obtained was 0.83 for $F$. vesiculosus from the Norwegian Sea, 0.78 for $F$. vesiculosus from the Bothnian Sea and 0.80 for F. radicans. $\Delta F / F^{\prime}{ }_{\mathrm{m}}$ is the effective quantum yield measured in light. PAR was multiplied by 0.5 to allow for an equal involvement of the two photosystems (Beer et al., 2000; Nygård \& Dring, 2008).

The $x$ axis of the rapid light curve is presented as absorbed light $(\mathrm{PAR} \times \mathrm{AF} \times 0.5)$ and the PSII photochemical efficiency was measured as the maximum quantum yield $\left(Y_{0}\right)$ as recommended by Saroussi \& Beer (2007). $Y_{0}$ can also be expressed as $F_{\mathrm{v}} / F_{\mathrm{m}}$ where $F_{\mathrm{v}}$ is the variable fluorescence, difference between the maximum $\left(F_{\mathrm{m}}\right)$ and minimum fluorescence, and $F_{\mathrm{m}}$ is the maximum fluorescence reached on dark-adapted algae when all PSII reaction centres are closed (Krause \& Weis, 1991). An investigation by Gylle et al. (2011) indicated that an assumption of equal involvement of the two photosystems in marine and brackish ecotype of $F$. vesiculosus and $F$. radicans is an incorrect simplification. However, more studies have to be done before the exact involvement of PSI 
and PSII in the absolute ETR have been totally clarified. The $P_{\max }$ was calculated with Photosyn Assistant software (Ver. 1.1.2, Dundee Scientific, Dundee, Scotland, UK).

Net photosynthesis measured by oxygen evolution

When the Bothnian Sea ecotype of $F$. vesiculosus had been treated for 1 week in BSW, 5, 10, 20 or 35 psu, net photosynthesis was measured as oxygen evolution with an oxygen electrode (Rank Brothers Ltd, DM 10, Cambridge, England). Measurements were performed in a saturated inorganic carbon environment $(3 \mathrm{mM}$ $\mathrm{NaHCO}_{3}$ ), using the vegetative tips of the thallus (precut $24 \mathrm{~h}$ before measurement). The sample was placed in a vertical position above a magnetic stirrer and facing the light projector. Light periods $(5 \mathrm{~min})$ with increasing irradiance in eight steps between 0 and $300 \mu \mathrm{mol}$ photons $\mathrm{m}^{-2} \mathrm{~s}^{-1}$ were used, interrupted by dark periods of $5 \mathrm{~min}$. In the salinity-treated Bothnian Sea ecotype of $F$. vesiculosus, efficiency of use of the absorbed light in photosynthesis at limiting irradiance $(\alpha)$ was calculated from the light-limited initial slope of the photosynthesis/irradiance curve ( $P / I$ curve) between three data points from 0 to $35 \mu \mathrm{mol}$ photons $\mathrm{m}^{-2} \mathrm{~s}^{-1}$. $P_{\max }$ was calculated with Photosyn Assistant software.

\section{Protein extraction}

For immunoblotting, proteins from $75 \mathrm{mg}$ of tissue were extracted in $1.5 \mathrm{~mL}$ of buffer according to a protocol modified from Li et al. (1998). The buffer ( $\mathrm{pH}$ 7.4) contained $100 \mathrm{mM}$ sodium ascorbate (KEBO Lab, Stockholm, Sweden), $50 \mathrm{mM}$ sodium 3-[Nmorpholino] propane sulfonic acid (MOPS), $3 \mathrm{mM}$ EDTA, $5 \mathrm{mM}$ dithiothreitol (DTT), 2\% polyvinylpolypyrrolidone (PVPP), $12 \mathrm{mM} 3$-[(3-cholamidopropyl) dimethyl-ammonio]1-propanesulfonate (CHAPS), $2 \%$ Triton X-100 and $10 \mu \mathrm{L}$ protease Inhibitor Cocktail (Sigma-Aldrich). Aliquots of the protein extracts were stored at $-80^{\circ} \mathrm{C}$ until SDS-PAGE and immunoblotting analysis. For spectrophotometric determination of Chl $a$ and $\mathrm{Chl} c\left(c_{1}\right.$ and $\left.c_{2}\right)$ concentrations, $90 \%$ acetone was used and the absorbance was measured at 630, 664 and $750 \mathrm{~nm}$ (Varian Cary 50 Scan, Agilent Technologies, Santa Clara, CA, USA; Porra, 1991).
SDS-PAGE and immunoblotting

Proteins in the solubilised samples containing $5 \mu \mathrm{g}$ Chl $a$ were used for the detection of D1 and PsaA proteins and $1 \mu \mathrm{g}$ Chl $a$ for the detection of Rubisco. The proteins were electrophoretically separated in a $15 \%(\mathrm{w} / \mathrm{v})$ polyacrylamide resolving gel containing $6 \mathrm{M}$ Urea, $0.66 \mathrm{M}$ Tris $(\mathrm{pH} 8.8)$ and a $5 \%(\mathrm{w} / \mathrm{v})$ polyacrylamide stacking gel-containing $0.125 \mathrm{M}$ Tris (pH 6.8) using the discontinuous Laemmli buffer system (Laemmli, 1970). Electrophoresis was performed at room temperature in a Mini-Protean II apparatus (Bio-Rad, Hercules, CA USA) for $1 \mathrm{~h}$ at $3 \mathrm{~mA}$. Protein standards (Bio-Rad, item number 161-0304) and protein extracts for all treatments were separated by SDS-PAGE and transferred electrophoretically to $5 \%(\mathrm{w} / \mathrm{v})$ BSA blocked nitrocellulose membranes (Bio-Rad) and probed using the PsbA polyclonal total IgY antibody (anti-D1, PSII), 1:50,000 dilution; PsaA polyclonal antibody (antiPSI-A), 1:500 dilution and global RbcL polyclonal antibody (anti-Rubisco), 1:5,000 dilution (Agrisera, Umeå, Sweden). After incubation with the secondary antibody $\operatorname{IgY}$, conjugated to peroxidise, for PsbA (Sigma-Aldrich, 1:10,000 dilution); IgG, conjugated to horseradish peroxidase, for PsaA and Rubisco (Agrisera, 1:50,000 dilution and Abcam, Cambridge, MA, USA, 1:20 000 dilution, respectively), the antibody-protein complexes were visualised using ECL chemiluminescence detection reagents (GE Healthcare, Waukesha, WI, USA) and developed on X-OMAT film (VWR, East Grinstead, United Kingdom). To obtain sharp bands, the optimal concentrations of Chl $a$ and antibodies were determined in preliminary tests. The immunoblotting was repeated 5-7 times for each replicate and for each class of protein and the developed photos were analysed by using Image J software (developed by Rasband (19972011), National Institutes of Health, Bethesda, MD, USA; use reference, Shim et al., 2010).

\section{Data analysis}

To analyse the differences, a general linear model analysis of variance (GLM) or one-way ANOVA, followed by Tukey's pairwise comparison, were performed. All factors were categorical and fixed. Tukey's pairwise comparison was performed for a complete comparison of all parts included in the 
experiments. The confidence intervals were set to $95 \%$. The standard deviation values are given in the figures and tables.

\section{Results}

Photosynthesis and relative amounts of D1, PsaA and Rubisco proteins in $F$. vesiculosus and $F$. radicans

To analyse the photosynthesis and to see if photosynthetic differences were connected with the relative amounts of D1, PsaA and/or Rubisco in the Fucus strains, analyses of $P / I$ curves (by ETR) and immunoblotting were performed (Figs. 1, 2; Table 1).

The results confirm that $P_{\max }$ was significantly higher (57\%) in the marine ecotype of $F$. vesiculosus compared to the brackish ecotype of $F$. vesiculosus $(P<0.01$; Fig. 1 ; Table 1$)$. The $P_{\max }$ was also significantly higher $(51 \%)$ in the marine ecotype of $F$. vesiculosus compared to $F$. radicans $(P<0.01$; Fig. 1; Table 1). No differences between the brackish Fucus species were detected. The results did not indicate any differences in $Y_{0}$ between the Fucus strains (Table 1).
The results from the estimations of the relative amounts of the D1 protein on a Chl $a$ basis did not indicate any significant differences between the two ecotypes of $F$. vesiculosus or between the two brackish Fucus species (Fig. 2a). Between the marine ecotype of $F$. vesiculosus and $F$. radicans, however, a significant difference could be detected with a greater relative amount of $\mathrm{D} 1$ protein in $F$. vesiculosus $(P<0.01$; Fig. 2 a). The measurements of PsaA protein showed that all three Fucus strains contained similar amounts of PsaA on a Chl $a$ basis (Fig. 2b). No significant differences in the relative PSII/PSI ratios were detected between any of the Fucus strains (Table 1). The results from the immunoblotting of Rubisco indicated that the relative amount of Rubisco in both strains of $F$. vesiculosus was almost double that in $F$. radicans $(P<0.001$; Fig. $2 \mathrm{c})$.

Effect of salinity on net photosynthesis and the relative amounts of D1, PsaA and Rubisco proteins in the brackish, Bothnian Sea ecotype of $F$. vesiculosus

To test if changes in photosynthetic variables were connected with the relative amounts of D1, PsaA and Rubisco when the brackish ecotype of $F$. vesiculosus

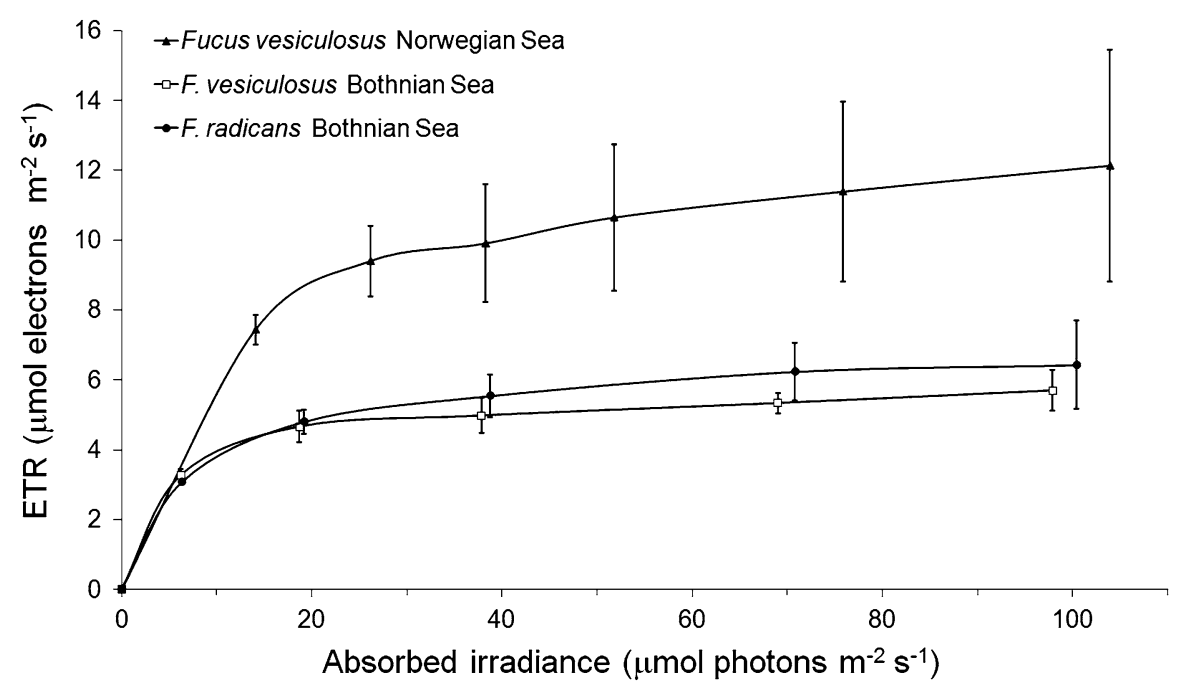

Fig. 1 Photosynthesis/irradiance curve measured by electron transport in marine $F$. vesiculosus from the Norwegian Sea (35 practical salinity units, psu) and brackish $F$. vesiculosus and $F$. radicans from the Bothnian Sea (4-5 psu). The measurements were completed after an initial dark-adaptation of $20 \mathrm{~min}$ and nine steps with increasing irradiance between 0 and $700 \mu \mathrm{mol}$ photons $\mathrm{m}^{-2} \mathrm{~s}^{-1}$ were used (points with incident irradiance above $250 \mu \mathrm{mol}$ photons $\mathrm{m}^{-2} \mathrm{~s}^{-1}$ are not shown). Data represent means of five replicates \pm standard deviation 

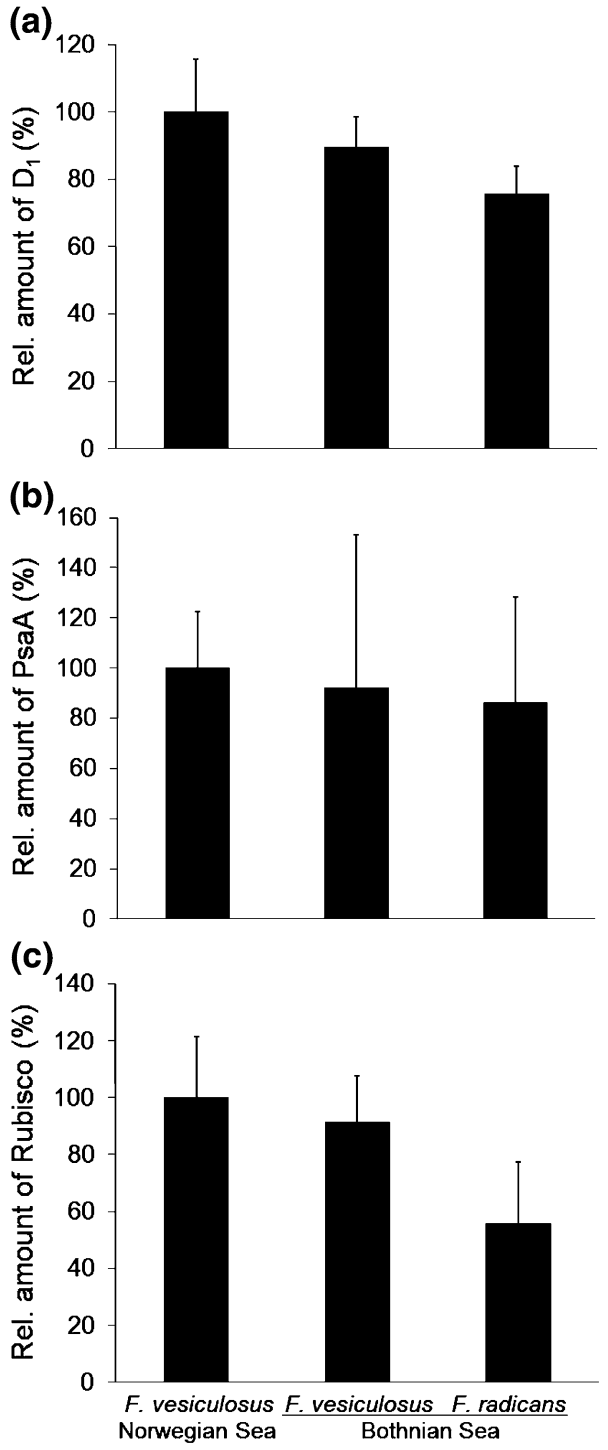

Fig. 2 The relative amounts of a D1 protein in photosystem II (PSII). b PsaA protein in PSI and c ribulose-1,5-bisphosphate carboxylase/oxygenase (Rubisco) in marine $F$. vesiculosus from the Norwegian Sea (35 practical salinity units, psu) and brackish $F$. vesiculosus and $F$. radicans from the Bothnian Sea (4-5 psu) were determined by immunoblotting and by ImageJ software. Data were represent means of ten replicates blotted 5-7 times each (for each protein) \pm standard deviation. Different letters indicate significant $(P<0.05)$ difference between the Fucus strains and lack of letter means no differences compared to the other Fucus strains. The $y$ axis presents the results in percent relative to the marine $F$. vesiculosus

was affected by salinity, the alga was treated in a range of salinities and analyses of $P / I$ curves (by $\mathrm{O}_{2}$ evolution) and immunoblotting were performed (Figs. 3, 4; Table 2).
Short-term salinity treatments had an effect on $P_{\max }$. The algae treated at salinities of 10 and $20 \mathrm{psu}$ had significantly higher $P_{\max }$ values than those at BSW or 5 psu $(P<0.01)$ and the algae treated at 35 psu had significantly higher $P_{\max }$ values than those at BSW $(P<0.05$; Fig. 3 ; Table 2$)$. The algae treated at 10 psu had also significantly higher $P_{\max }$ than algae treated in 35 psu $(P<0.05$; for details in significant differences in $P_{\max }$ between the treatments see Table 2). Photosynthetic efficiency $(\alpha)$ was largely unaffected but it was significantly lower in algae treated in BSW compared to algae treated in $20 \mathrm{psu}$ (Fig. 3; Table 2).

The immunoblotting did not indicate any effects of salinity on the relative amounts of D1 protein or Rubisco on a Chl $a$ basis in the brackish ecotype of F. vesiculosus (Fig. 4a, c). In contrast, the relative amount of PsaA protein in PSI on a Chl $a$ basis showed significantly greater amounts of PsaA in algae treated in 10 psu compared to algae treated in BSW and in 35 psu $(P<0.05$; Fig. 4 b). The PSII/PSI ratio, measured by immunoblot signals of D1/PsaA, was significantly lower in algae treated in 10 psu (0.45) than in algae treated in 35 psu $(0.72 ; P<0.05$; Table 2$)$.

\section{Discussion}

Photosynthesis and relative amounts of D1, PsaA and Rubisco proteins in $F$. vesiculosus and $F$. radicans

The results indicated a higher $P_{\max }$ in the marine ecotype of $F$. vesiculosus than in the brackish ecotype of $F$. vesiculosus and $F$. radicans (Fig. 1; Table 1). The lower $P_{\max }$ in the brackish water Fucus than in the marine ecotype of $F$. vesiculosus is in line with earlier investigations (Bäck et al., 1992; Nygård \& Ekelund, 2006; Nygård \& Dring, 2008). In this study we made a first attempt to reveal what causes the differences in $P_{\text {max }}$ between the Fucus strains by immunoblotting of D1, PsaA and Rubisco. Immunoblot signals in the detections of D1 and PsaA showed a similar D1/PsaA ratio in all three Fucus strains. The results suggest, however, an uneven photosystem protein stoichiometry in Fucus, with more of the PSI protein PsaA relative to the PSII protein D1 (Table 1). This difference between PSI and PSII appears to be in agreement with $77 \mathrm{~K} \mathrm{Chl} a$ fluorescence emission 
Table 1 Photosynthetic maximum capacity $\left(P_{\max }\right)$ measured by electron transport, the efficiency to use absorbed light in photosynthesis (maximum quantum yield, $Y_{0}$ ) and the relative
D1/PsaA ratio in marine $F$. vesiculosus from the Norwegian sea (35 practical salinity units, psu) and brackish $F$. vesiculosus and $F$. radicans from the Bothnian Sea (4-5 psu)

\begin{tabular}{lrrr}
\hline Algae & \multicolumn{1}{c}{$P_{\max }$} & $Y_{\mathrm{o}}$ & D1/PsaA \\
\hline F. vesiculosus Norwegian Sea & $13.0^{\mathrm{A}} \pm 4.33$ & $0.70 \pm 0.030$ & $0.38 \pm 0.077$ \\
F. vesiculosus Bothnian Sea & $5.6^{\mathrm{B}} \pm 0.46$ & $0.70 \pm 0.017$ & $0.40 \pm 0.115$ \\
F. radicans Bothnian Sea & $6.4^{\mathrm{B}} \pm 1.49$ & $0.70 \pm 0.010$ & $0.35 \pm 0.086$
\end{tabular}

The mean and \pm standard deviation values of $P_{\max }$ and $Y_{\mathrm{o}}$ are based on five replicates. D1and PsaA were determined by immunoblotting and by ImageJ software and the data represent means of ten replicates blotted 5-7 times each (for each protein) \pm standard deviation. Different superscript letters indicate significant $(P<0.05)$ difference between the Fucus strains and lack of superscript letter means no differences compared to the other Fucus strains. The expressed D1/PsaA ratio (PSII/PSI) is the ratio of the immunoblot signals, not the absolute molar ratio of the complexes and therefore, the comparison can only be interpreted as a relative indicator of PSII/PSI

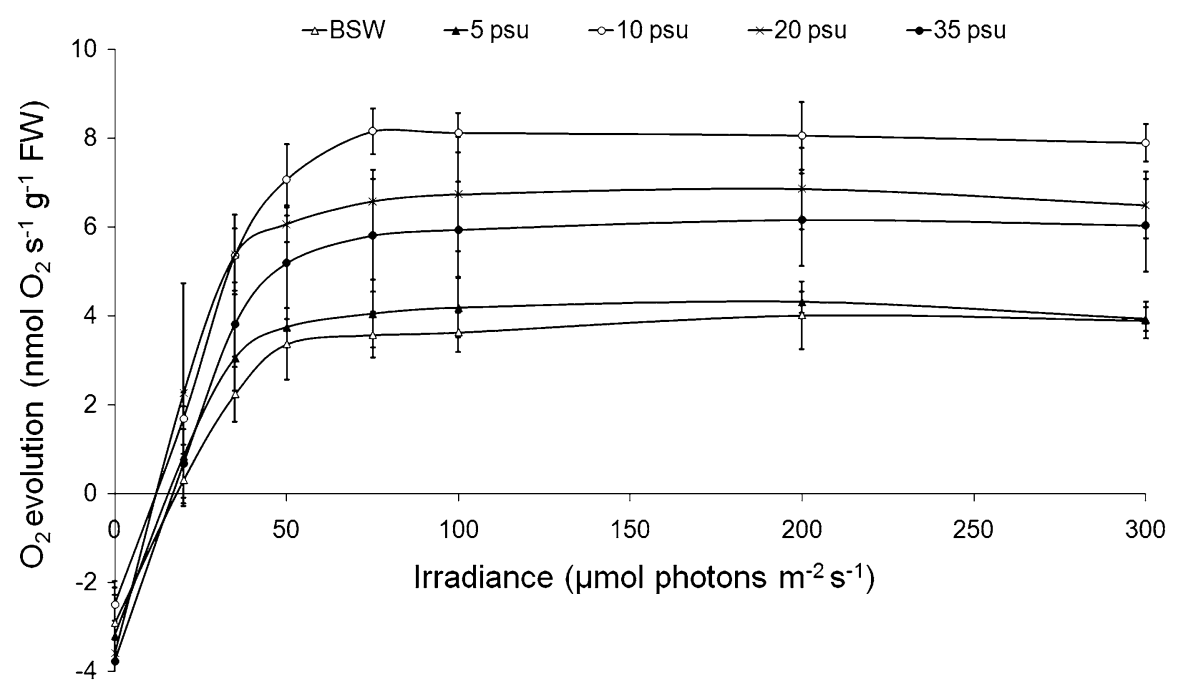

Fig. 3 Photosynthesis/irradiance curve measured by oxygen evolution in brackish $F$. vesiculosus from the Bothnian Sea (4-5 practical salinity units, psu) treated for 1 week in Bothnian seawater (BSW) or in artificial sea water at different salinities (5, $10,20$ or $35 \mathrm{psu})$. The light $\left(90 \mu \mathrm{mol}\right.$ photons $\left.\mathrm{m}^{-2} \mathrm{~s}^{-1}\right)$ :dark

spectra for the marine $F$. vesiculosus (PSII/ $\mathrm{PSI} \sim 0.3$ ) and $F$. radicans $(\mathrm{PSII} / \mathrm{PSI} \sim 0.4$; Gylle et al., 2011). $77 \mathrm{~K}$ fluorescence emission of the brackish ecotype of $F$. vesiculosus, however, showed a PSII/PSI ratio $\sim 1$ in Gylle et al. (2011). The reason for the higher fluorescence emission in PSII in the brackish $F$. vesiculosus, than in the other Fucus strains, was concluded to be due to larger lightharvesting antenna of PSII and not due to a truly higher PSII/PSI ratio (Gylle et al., 2011). This interpretation of the $77 \mathrm{~K}$ fluorescence emission of the brackish ecotype of $F$. vesiculosus in Gylle et al. (2011) appears period was 12:12 h. The measurements were completed after an initial dark-adaptation of $20 \mathrm{~min}$ and eight steps with increasing irradiance between 0 and $300 \mu \mathrm{mol}$ photons $\mathrm{m}^{-2} \mathrm{~s}^{-1}$ were used. Data were represent means of five replicates \pm standard deviation

to be in line with the immunoblot signals of D1/PsaA (Table 1). The PSII/PSI ratio differ between different organisms and have been observed to be 1.43-1.72 in some terrestrial plants, 0.43 in blue-green algae and 0.84-1.03 in some green algae (Melis \& Brown, 1980; Falkowski et al., 1981; Yamazaki et al., 2005; Fan et al., 2007).

The reasons for generally lower PSII/PSI ratio in marine algae compared to terrestrial plants have been suggested to be: (1) a need of greater ATP/NADPH ratio as energy to import various nutrients and therefore more PSI to mediate cyclic electron 


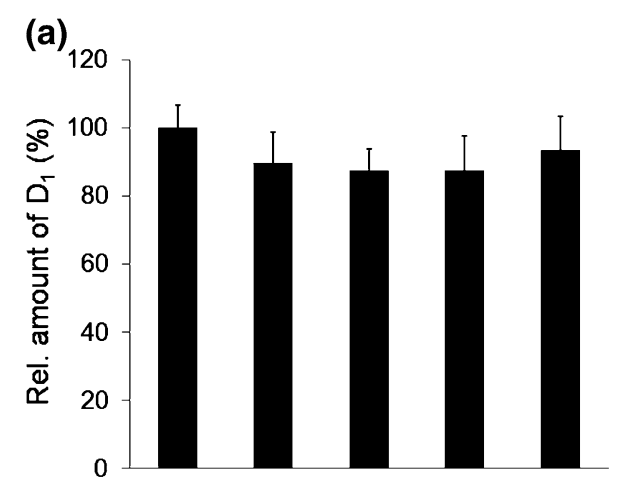

(b)
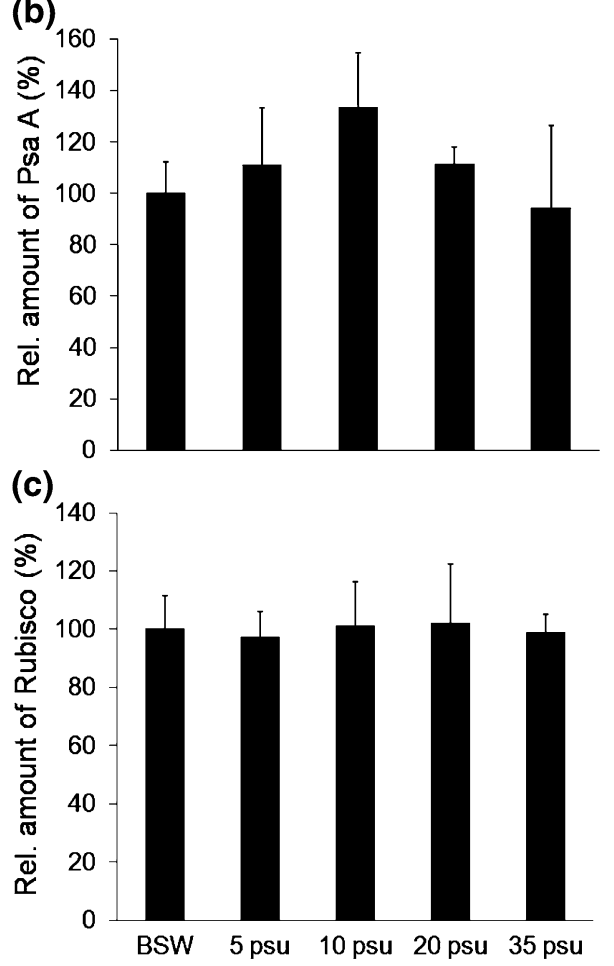

Fig. 4 The relative amounts of a D1 protein in photosystem II (PSII). b PsaA protein in PSI and c ribulose-1,5-bisphosphate carboxylase/oxygenase (Rubisco) in brackish F. vesiculosus from the Bothnian Sea (4-5 practical salinity units; psu) were determined by immunoblotting and by ImageJ software. The algae were treated for 1 week in Bothnian seawater (BSW) or in artificial sea water at different salinities $(5,10,20$ or 35 psu). The light $\left(90 \mu \mathrm{mol}\right.$ photons $\left.\mathrm{m}^{-2} \mathrm{~s}^{-1}\right)$ :dark period was 12:12 $\mathrm{h}$. Data represent means of five replicates blotted 5-7 times each (for each protein) \pm standard deviation. Different letters indicate significant $(P<0.05)$ difference between the treatments and lack of letter means no differences compared to the other treatments. The $y$ axis presents the results in percent relative to the algae treated in BSW transport, and (2) the imbalance in the photosystem stoichiometry protects algae from photoinhibition in the blue-green light that preferentially excites PS II (Yamazaki et al., 2005).

Because of the differences in $P_{\max }$ (Fig. 1; Table 1), it was hypothesised that the marine ecotype of $F$. vesiculosus would have more Rubisco than both the brackish Fucus species. Rubisco is accumulated in parallel with high photochemical activities (Björkman, 1981; Maayana et al., 2008). The results, however, showed approximately the same relative amount of Rubisco in both ecotypes of $F$. vesiculosus whereas $F$. radicans had about half the amount (Fig. 2c). These results indicated that the reasons for the lower $P_{\max }$ in the brackish ecotype of $F$. vesiculosus and $F$. radicans than in the marine ecotype of $F$. vesiculosus might originate from different underlying causes. Whereas the relatively lower amount of Rubisco may be an important part of the explanation of the low $P_{\max }$ in $F$. radicans, there may be another explanation for the low $P_{\text {max }}$ in the brackish ecotype of $F$. vesiculosus. The difference in $P_{\max }$ between the two ecotypes of $F$. vesiculosus might be related to the difficulties for the algae to adapt to the environment in Bothnian Sea or to normal differences in environmental adaptations. Further investigations are needed in order to understand the low $P_{\max }$ in the brackish ecotype of $F$. vesiculosus and we suggest measuring the rate of $\mathrm{CO}_{2}$ fixation by Rubisco as a first step. Only few investigations have been done on the recently discovered $F$. radicans and it is important to keep in mind that $F$. radicans, unlike the brackish ecotype of $F$. vesiculosus, is a native species in the Bothnian Sea environment. It is interesting to note the similarity in $P_{\max }$ between the Bothnian Sea Fucus species despite lower relative amount of Rubisco in $F$. radicans pointing towards a more efficient $\mathrm{CO}_{2}$ fixation in $F$. radicans. A speculation worth take in consideration is that the brackish ecotype of $F$. vesiculosus compared to the marine ecotype and $F$. radicans might have a less efficient $\mathrm{C} 4$-like pathway to accumulate $\mathrm{CO}_{2}$. This may increase a need of higher amount of Rubisco, relative to the $P_{\max }$, in the brackish ecotype of F. vesiculosus. Wang et al. (2011) showed higher abundance and activity of Rubisco in gametophytes compared to sporophytes and assumed that a more marked C4-like pathway supply the sporophytes 
Table 2 Photosynthetic maximum capacity $\left(P_{\max }\right)$ measured by oxygen evolution (nmol $\mathrm{O}_{2} \mathrm{~s}^{-1} \mathrm{~g}^{-1} \mathrm{FW}$ ), the efficiency to use absorbed light in photosynthesis at limiting irradiance $(\alpha$ : calculated between 0 and $35 \mu \mathrm{mol}$ photons $\mathrm{m}^{-2} \mathrm{~s}^{-1}$ ) and the relative D1/PsaA ratio in the brackish Bothnian Sea (4-5 practical salinity units, psu) $F$. vesiculosus after 1 week treatment in Bothnian seawater (BSW) or in artificial seawater at different salinities (ASW of 5, 10, 20 or 35 psu)

\begin{tabular}{llll}
\hline Treatment & $P_{\max }$ & $\alpha$ & D1/PsaA \\
\hline BSW & $4.2^{\mathrm{AA}} \pm 0.92$ & $0.15^{\mathrm{A}} \pm 0.017$ & $0.69^{\mathrm{A}} \pm 0.111$ \\
$5 \mathrm{psu}$ & $4.6^{\mathrm{AD}} \pm 0.49$ & $0.18^{\mathrm{B}} \pm 0.038$ & $0.56^{\mathrm{A}} \pm 0.088$ \\
$10 \mathrm{psu}$ & $8.8^{\mathrm{BB}} \pm 1.35$ & $0.22^{\mathrm{B}} \pm 0.064$ & $0.45^{\mathrm{A}} \pm 0.071$ \\
$20 \mathrm{psu}$ & $7.7^{\mathrm{BC}} \pm 1.08$ & $0.26^{\mathrm{B}} \pm 0.043$ & $0.52^{\mathrm{A}} \pm 0.097$ \\
$35 \mathrm{psu}$ & $6.4^{\mathrm{CD}} \pm 1.20$ & $0.22^{\mathrm{B}} \pm 0.070$ & $0.72^{\mathrm{B}} \pm 0.239$
\end{tabular}

The light $\left(90 \mu \mathrm{mol}\right.$ photons $\left.\mathrm{m}^{-2} \mathrm{~s}^{-1}\right)$ :dark period was $12: 12 \mathrm{~h}$. The values are mean values \pm standard deviations from five replicates. D1 and PsaA was determined by immunoblotting and by ImageJ software and each of the five replicates were blotted 5-7 times (for each protein). Different superscript letters indicate significant $(P<0.05)$ difference between the treatments and lack of superscript letter means no differences compared to the other treatments. The expressed D1/PsaA ratio (PSII/PSI) is the ratio of the immunoblot signals, not the absolute molar ratio of the complexes and, therefore, the comparison can only be interpreted as a relative indicator of PSII/PSI

with $\mathrm{CO}_{2}$ and made it unnecessary to have a high abundance of Rubisco.

Effect of salinity on net photosynthesis and relative amounts of D1, PsaA and Rubisco of the brackish, Bothnian Sea, ecotype of $F$. vesiculosus

In general, there were higher $P_{\max }$ values in the brackish ecotype of $F$. vesiculosus treated in the higher salinities, 10,20 and $35 \mathrm{psu}$, compared to $P_{\max }$ in algae treated in BSW and 5 psu. The most favourable salinity was 10 psu followed by 20 psu (Table 2). These results were in line with earlier ETR measurements when the alga was treated in different salinities together with low or high concentrations of dissolved inorganic carbon and nutrients (Nygård \& Dring, 2008).

In this first attempt to explain the differences in the $P_{\max }$ of the brackish $F$. vesiculosus treated in different salinities we did not observe any differences in the relative amount of either D1 or Rubisco (Fig. 4a, c). The relative amount of PsaA protein (Fig. 4b) and the D1/PsaA ratio (Table 2), however, indicated a salinity effect. The relative amount of PsaA was greatest in algae treated in 10 psu and it was significantly greater in 10 psu compared to algae treated in BSW and 35 psu. The greater amount of PsaA in algae treated in 10 psu was in line with the photosynthetic measurements (Fig. 3; Table 2). The explanation might be that the algae need to produce more ATP, and greater amount of PsaA may increase the possibility to have a greater flow of cyclic electron transport around PSI to serve a higher rate of $\mathrm{CO}_{2}$ concentrating mechanisms and/or a higher rate of $\mathrm{CO}_{2}$ fixation by Rubisco. It has earlier been confirmed that greater relative amounts of PSI and greater cyclic electron flow around PSI might occur in conditions with an increased need for ATP (Mandori \& Melis, 1984; Anderson et al., 1995; Tanaka et al., 1997; Hall \& Rao, 1999; Yamazaki et al., 2005). Gao et al. (2011) have also showed that the electron flow around PSI was significantly elevated in Ulva sp. during desiccation which indicates that PSI-driven cyclic electron flow might provide some protection of the photosynthetic apparatus and extra ATP under stress conditions. As a consequence of more PsaA, the D1/PsaA ratio was lowest in algae treated in 10 psu and significantly lower relative to the algae treated in 35 psu (Table 2). Earlier studies have confirmed a change in PSII/PSI ratio as a response to $\mathrm{CO}_{2}$ supply, irradiance, nitrogen supply and because of salinity shock (Mandori \& Melis, 1984; Kim et al., 1993; Berges et al., 1996; Tanaka et al., 1997). It is tempting to speculate that an increased amount of ATP might be used to serve a more efficient C4-like pathway and thereby an accumulation of $\mathrm{CO}_{2}$.

The indicated lower D1/PsaA ratio in algae treated in $10 \mathrm{psu}$ in Table 2 was not in line with $77 \mathrm{~K}$ fluorescence emission spectra (Gylle et al., 2011) and in order to understand what causes the differences between the studies we suggest an investigation of the light-harvesting antenna proteins as a first step.

Acknowledgments Thanks to Dr. Dan Isaksson and Robert Nordström for help with diving and algae collection. Thanks also to Dr. Esa Tyystjärvi at University of Turku for valuable opinions. 
Open Access This article is distributed under the terms of the Creative Commons Attribution License which permits any use, distribution, and reproduction in any medium, provided the original author(s) and the source are credited.

\section{References}

Anderson, J. M., W. S. Chow \& Y. I. Park, 1995. The grand design of photosynthesis: acclimation of the photosynthetic apparatus to environmental cues. Photosynthesis Research 46: 129-139.

Beer, S., C. Larsson, O. Poryan \& L. Axelsson, 2000. Photosynthetic rates of Ulva (Chlorophyta) measured by pulse amplitude modulated (PAM) fluorometry. European Journal of Phycology 35: 69-74.

Berges, J. A., D. O. Charlebois, D. C. Mauzerall \& P. G. Falkowski, 1996. Differential effects of nitrogen limitation on photosynthetic efficiency of photosystems I and II in microalgae. Plant Physiology 110: 689-696.

Bergström, L., A. Tatarenkov, K. Johannesson, R. B. Jönsson \& L. Kautsky, 2005. Genetic and morphological identification of Fucus radicans sp. Nov (Fucales, Phaeophyceae) in the brackish Baltic Sea. Journal of Phycology 41: 1025-1038.

Björkman, O., 1981. Responses to different quantum flux densities. In Lange, O. L., P. S. Nobel, C. B. Osmond \& H. Ziegler (eds), Encyclopedia of plant physiology, vol 12. Physiological plant ecology. I. Responses to physical environment. Springer, New York, NY: 57-107.

Bäck, S., J. C. Collins \& G. Russel, 1992. Comparative ecophysiology of Baltic and Atlantic Fucus vesiculosus. Marine Ecology Progress Series 84: 71-82.

Falkowski, P. G., T. G. Owens, A. C. Ley \& D. C. Mauzerall, 1981. Effects of growth irradiance levels on the ratio of reaction centers in two species of marine phytoplankton. Plant Physiology 68: 969-973.

Fan, D.-Y., A. B. Hope, P. J. Smith, H. Jia, R. J. Pace, J. M. Anderson \& W. S. Chow, 2007. The stoichiometry of the two photosystems in higher plants revisited. Biochimica et Biophysica Acta 1767: 1064-1072.

Gao, S., S. Shen, G. Wang, J. Niu, A. Lin \& G. Pan, 2011. PSIdriven electron flow allows intertidal macro-algae Ulva sp. (Chlorophyta) to survive in desiccated conditions. Plant Cell Physiology 52: 885-893.

Gylle, A. M., C. A. Nygård \& N. G. A. Ekelund, 2009a. Desiccation and salinity effects on marine and brackish Fucus vesiculosus L. (Phaeophyceae). Phycologia 48: 156-164.

Gylle, A. M., D. Isaksson \& N. G. A. Ekelund, 2009b. Ecotype differentiation in qualitative content of water soluble organic compounds between marine and brackish Fucus vesiculosus L. (Phaeophyceae). Phycological Research 57: 127-130.

Gylle, A. M., S. Rantamäki, N. G. A. Ekelund \& E. Tyystjärvi, 2011. Fluorescence emission spectra of marine and brackish-water ecotypes of Fucus vesiculosus and Fucus radicans (Phaeophyceae) reveal differences in light-harvesting apparatus. Journal of Phycology 47(1): 98-105.

Hall, D. O. \& K. K. Rao, 1999. Photosynthesis. Cambridge University Press, Cambridge.
Kalvas, A. \& L. Kautsky, 1993. Geographical variation in Fucus vesiculosus morphology in the Baltic and North Seas. European Journal of Phycology 28: 85-91.

Kim, J. H., R. E. Click \& A. Melis, 1993. Dynamics of photosystem stoichiometry adjustment by light quality in chloroplasts. Plant Physiology 102: 181-190.

Krause, G. H. \& E. Weis, 1991. Chlorophyll fluorescence and photosynthesis: the basics. Annual Review of Plant Physiology and Plant Molecular Biology 42: 313-349.

Laemmli, U. K., 1970. Cleavage of structural proteins during the assembly of the head of bacteriophage T4. Nature 227: 680-685.

Li, R., S. H. Brawley \& T. J. Close, 1998. Proteins immunologically related to dehydrins in Fucoid algae. Journal of Phycology 34: 642-650.

Maayana, I., F. Shayaa, K. Ratnera, Y. Mania, S. Laveeb, B. Avidana, J. Shahaka \& O. Ostersetzer-Birana, 2008. Photosynthetic activity during olive (Olea europaea) leaf development correlates with plastid biogenesis and Rubisco levels. Physiologia Plantarum 134: 547-558.

Mandori, A. \& A. Melis, 1984. Photochemical apparatus organization in Anacystis nidulans (Cyanophyceae); effect of $\mathrm{CO}_{2}$ concentration during cell growth. Plant Physiology 74: 67-71.

Melis, A. \& J. S. Brown, 1980. Stoichiometry of system I and system II reaction centers and of plastoquinone in different photosynthetic membranes (photoreaction/electron transport/spectrophotometry/chloroplast function/P700-chlorophyll). Proceedings of the National Academy of Sciences of the United States of America 77: 4712-4716.

Nixon, P. J., M. Barker, M. Boehm \& R. de Vries, 2005. FtsHmediated repair of the photosystem II complex in response to light stress. Journal of Experimental Botany 56: 357-363.

Nixon, P. J., F. Michoux, J. Yu, M. Boehm \& J. Komenda, 2010. Recent advances in understanding the assembly and repair of photosystem II. Annals of Botany 106: 1-16.

Nygård, C. A. \& N. G. A. Ekelund, 2006. Photosynthesis and UV-B tolerance of the marine alga Fucus vesiculosus at different sea water salinities. Journal of Applied Phycology 18: 461-467.

Nygård, C. A. \& M. J. Dring, 2008. Influence of salinity, temperature, dissolved inorganic carbon and nutrient concentration on the photosynthesis and growth of Fucus vesiculosus from the Baltic and Irish Seas. European Journal of Phycology 43: 253-262.

Pearson, G., L. Kautsky \& E. Serrão, 2000. Recent evolution in Baltic Fucus vesiculosus: reduced tolerance to emersion stresses compared to intertidal (North Sea populations. Marine Ecology Progress Series 202: 67-79.

Porra, R. J., 1991. Recent advances and re-assessments in chlorophyll extraction and assay procedures for terrestrial, aquatic, and marine organisms, including recalcitrant algae. In Scheer, H. (ed.), Chlorophylls. CRC Press, Boca Raton, FL, USA: 31-57.

Powell, H. T., 1963. Speciation in the genus Fucus L. and related genera. In Harding, J. P. \& N. Tebble (eds), Speciation in the sea. Systematic Association Publication, London, UK: 63-77.

Rasband, W. S., 1997-2011. ImageJ, U. S. National Institutes of Health, Bethesda, MD, USA. http://rsb.info.nih.gov/ij/. Accessed on 02 Dec 2011. 
Raven, J., 1997. Putting the C in phycology. European Journal of Phycology 32: 319-333.

Raven, J. A. \& G. Samuelsson, 1988. Ecophysiology of Fucus vesiculosus $\mathrm{L}$. close to its northern limit in the Gulf of Bothnia. Botanica Marina 31: 399-410.

Ruuskanen, A. \& S. Bäck, 1999. Morphological variation of northern Baltic Sea Fucus vesiculosus L. Ophelia 50: 43-59.

Santabarbara, S., L. Galuppini \& A. P. Casazza, 2010. Bidirectional electron transfer in the reaction centre of photosystem I. Journal of Integrative Plant Biology 52: 735-749.

Saroussi, S. \& S. Beer, 2007. Alpha and quantum yield of aquatic plants derived from PAM fluorometry: uses and misuses. Aquatic Botany 86: 89-92.

Shim, J. S., Y. Matsui, S. Bhat, B. A. Nacev, J. Xu, H.-E. C. Bhang, S. Dhara, K. Chung Han, C. R. Chong, M. G. Pomper, A. So \& J. O. Liu, 2010. Effect of nitroxoline on angiogenesis and growth of human bladder cancer. Journal of the National Cancer Institute 102: 1855-1873.

Tanaka, Y., S. Katada, H. Ishikawa, T. Ogawa \& T. Takabe, 1997. Electron flow from NAD(P)H dehydrogenase to photosystem I is required for adaptation to salt shock in the cyanobacterium Synechocystis sp. PCC 6803. Plant Cell Physiology 38: 1311-1318.

Wallentinus, I. 1979. Environmental influences on benthic macrovegetation in the Trosa-Askö area northern Baltic Proper. II The ecology of macroalgae and submersed phanerogams. PhD Thesis, University of Stockholm, Stockholm, Sweden.

Wang, C., X. Fan, G. Wang, J. Niu \& B. Zhou, 2011. Differential expression of Rubisco in sporophytes and gametophytes of some marine macroalgae. PLoS ONE 6: e16351.

Wærn, M., 1952. Rocky-shore algae in the Oregrund archipelago. Acta Phytogeographica Suecia 30: 1-298.

Yamazaki, J., T. Suzuki, E. Maruta \& Y. Kamimura, 2005. The stoichiometry and antenna size of the two photosystems in marine green algae, Bryopsis maxima and Ulva pertusa, in relation to the light environment of their natural habitat. Journal of Experimental Botany 56: 1517-1523. 